Original Research Paper

\title{
An NPV Optimization Model for Closed-Loop Supply Chain Network Design and Planning
}

\author{
${ }^{1,2}$ Al-Ashhab Mohamed Sayed and ${ }^{1}$ Nahid Afia \\ ${ }^{I}$ Department of Design and Production Engineering, Faculty of Engineering, Ain-Shams University, Egypt \\ ${ }^{2}$ Department of Mechanical Engineering, \\ College of Engineering and Islamic Architecture, Umm Al-Qura University, Makkah, Saudi Arabia
}

Article history

Received: 19-07-2016

Revised: 06-01-2017

Accepted: 17-02-2017

Corresponding Author: Al-Ashhab Mohamed Sayed Department of Mechanical Engineering, College of Engineering and Islamic Architecture, Umm Al-Qura University, Makkah, Saudi Arabia

Email: mohammedsem@yahoo.com

\begin{abstract}
As the importance of forward-reverse logistics increases, attention will be focused on parameters which affect Net Present Value (NPV) of the whole system, aiming at considering the time value of money in planning. In this research, an NPV optimization model for multi-period multi-product closed-loop supply chain network design and planning is developed to maximize the total NPV. The effect of interest rates on profit and performance, the effect of the maximum return ratio on the overall NPV of the system and the effect of interest rate change on the network configuration are studied.
\end{abstract}

Keywords: Supply Chain, Location-Allocation, Forward-Reverse Logistics, MILP, CLSC, NPV

\section{Introduction}

Companies nowadays have attracted the attention towards the performance and benefits of the forwardreverse supply chain. Understanding, categorizing returned products for disposition and managing reverse logistic programs can not only reduce costs but also offer many opportunities for additional revenues.

In the domain of CLSCN, It is preferable to establish a set of KPIs include returned goods as a percentage of sales; the ratio of costs savings; the rate of resource utilization; and growth of returns. The cash outflows and the future revenue inflows can be obtained in each period through the usage of the rate of return. The net present value of both cash inflows and cash outflows can be obtained and used as a mean of investment appraisal and valuing a future sum of money in today's terms.

Lee and Dong (2009) developed a two-stage stochastic programming model that integrates the SAA method with an SA based heuristic algorithm.

El-Sayed et al. (2010) developed a single product SMILP model for designing a forward-reverse logistics under demand risk.

Franca et al. (2010) introduced a multi-objective stochastic model that uses Six Sigma measures to evaluate financial risk in the supply chain.

Ramezani et al. (2013) present a robust optimization approach to the uncertainty of demand and the return rate described by a finite set of possible scenarios.

Subulan and Tasan (2013) introduce a mixed integer programming model which includes nonlinear constraints for the CLSC of a conceptual product with the objective of minimizing the total cost.

Baptista et al. (2013) studied the impact uncertainties which of transportation costs, demand and return volumes on the total expected supply chain profit. Applying their model to a case study, they solved two scenarios normal and worst case. A sensitivity analysis is performed to test the solution robustness. They concluded that, the value of perfect.

Diabet et al. (2013) developed a Mixed Integer NonLinear Programming (MINLP) model for product returns to minimize the total reverse logistics cost. They implemented and compared the genetic algorithm and artificial immune system for solving the model and demonstrated the application of the model.

Hatefi and Jolai (2014) formulated a single period and a single product robust and reliable model for a forward-reverse logistics network to protect the network against uncertainty.

Vahdani (2015) evaluates a closed-loop supply chain design problem that incorporates both strategic and tactical decisions under a fuzzy-stochastic environment to maximize NPV, minimize delivery time and maximize the chain flexibility. 
Jindal et al. (2015) developed a capacitated CLSC framework for an uncertain environment. The proposed framework and mathematical model can be customized for various industries.

Zeballos et al. (2016) presented a comprehensive risk-averse stochastic framework for the problem of design and planning CLSCs under uncertainty with a multistage stochastic approach. A sensitivity analysis of the approach performance considering changes in the parameters associated with the risk metrics is conducted.

Vahdani and Mohammadi (2015) developed a biobjective optimization model for the CLSC problem to minimize the total cost and the waiting time in services. Their model assumes that all activities occur in one period.

From the aforementioned, most of the closed loop supply chain CLSCN models are single period and little is multi-period. Few researchers consider the time value of money. Few others gather between designing and production planning with the integration of forward and reverse logistic activities.

The present work develops an MILP model to design and plan the multi-period, multi-product closed loop supply chain network design in order to maximize the net present value.

\section{Model Description}

The proposed closed loop supply chain network flow is as shown in Fig. 1.

\section{Model Formulation}

The sets, parameters and decision variables of the model are:

Sets:

- S, F, D and C: Potential number of suppliers, factories, distributors and first customers

- A, R, L and K: Potential number of disassembly, redistributors, locations, disposal and second clients

- P: Number of products

- T: Number of periods

- IR: The interest rate

\section{Parameters:}

- Dipt: Demand of location $i$ from product $p$ in period $t$

- Ppit: Unit price of product $p$ at location $i$ in period $t$

- Fi: Fixed cost of location $i$

- DSij: Distance between any two locations $i$ and $j$
- CAPSst: Supplier s capacity in period $\mathrm{t}(\mathrm{kg})$

- CAPMft: Raw material store capacity of facility $f$ in period $t(\mathrm{~kg})$

- CAPHft: Manufacturing hours capacity of facility $f$ in period $t$

- CAPFSft: Final product storing capacity of facility $f$ in period $t(\mathrm{~kg})$

- CAPDdt: Storing capacity of distributor $d$ in period $t$ $(\mathrm{kg})$

- CAPAat: Disassembly $a$ capacity in period $t$

- CAPRCst: Recycling capacity of supplier $s$ in period $t(\mathrm{~kg})$

- CAPRMft: Remanufacturing capacity in hours of factory $f$ in period $t$

- CAPRrt: Capacity of redistributor $r$ in period $t$

- CAPLit: Capacity of disposal $p$ in period $t$

- MatCst: Material cost per unit supplied by supplier $s$ in period $t$

- RECst: Recycling cost per unit recycled by supplier $s$ in period $t$

- MCft: Manufacturing cost per hour for factory $f$ in period $t$

- RMCft: Remanufacturing cost per hour for factory $f$ in period $t$

- DACat: Disassembly cost per unit weight disassembled by disassembly location $a$ in period $t$

- REPCat: Repairing cost per unit repaired by disassembly location $a$ in period $t$

- DISPClt: Disposal cost per unit disposed of by disposal location $l$ in period $t$

- NUCCf: Non-utilized manufacturing capacity cost per hour of facility $f$

- NURCCf: Non-utilized remanufacturing capacity cost per hour of factory $f$

- SCPUp: Shortage cost per unit per period for product $p$,

- MHp: Manufacturing hours for product $p$

- Wp: Weight of product $p$

- $\quad$ RMHp: Remanufacturing hours for product $p$

- FHf: Holding cost per unit weight per period at the store of factory $f$,

- DHd: Holding cost per unit weight per period at distributor store $d$,

- $\mathrm{Bs}, \mathrm{Bf}, \mathrm{Bd}, \mathrm{Ba}$ and Br: Batch size from supplier $s$, factory $f$, distributor $d$, disassembly $a$ and redistributor $r$ respectively

- Tc: Transportation cost per unit per kilometer RR: Maximum return ratio at the first customers

- RC: Recycling ratio

- RM: Remanufacturing ratio

- RP: Repairing ratio

- RD: Disposal ratio 


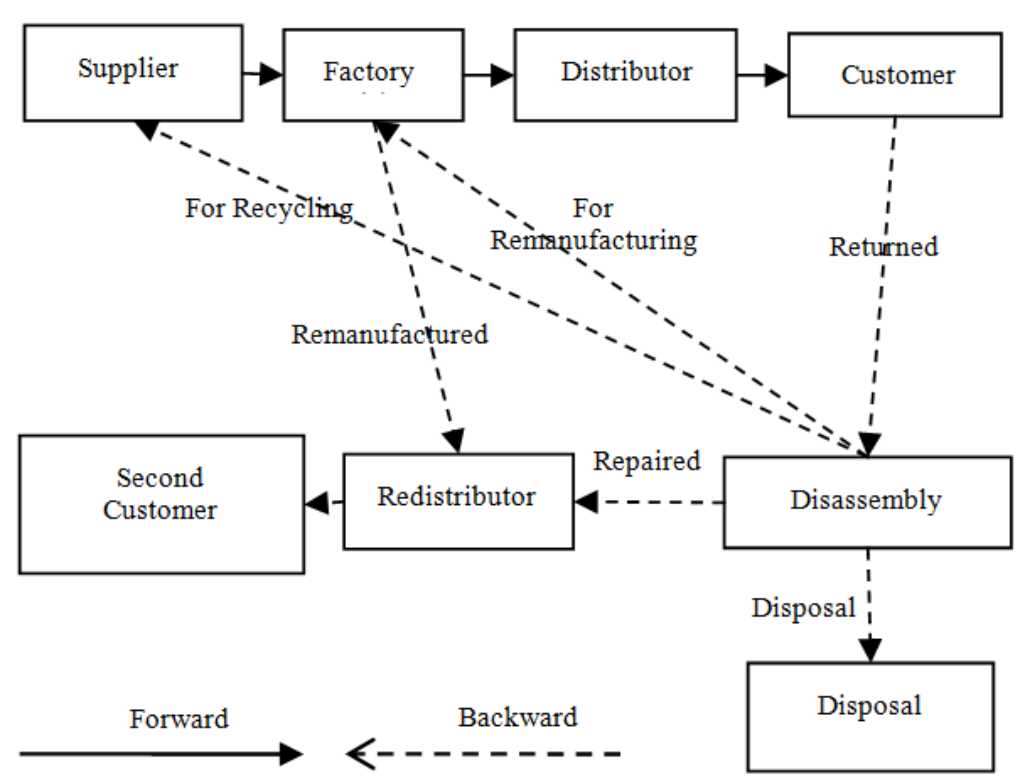

Fig. 1. The proposed network echelons

\section{Decision Variables}

- Li: Binary variable equals 1 if location $i$ is open and 0 otherwise

- Qijpt: Flow of batches from location $i$ to location $j$ of product $p$ in period $t$

- Ifpt: Flow of batches from factory $f$ to its store of product $p$ in period $t$

- Ifdpt: Flow of batches from store of factory $f$ to distributor $d$ of product $p$ in period $t$

- Rfpt: The residual inventory of product $p$ in the period $t$ at store of factory $f$

- Rdpt: The residual inventory of product $p$ in the period $t$ at distributor $d$

\section{Objective Function}

The objective of the model is to maximize NPV of the network.

$\mathrm{NPV}=$ Total Revenue NPV-Total Cost NPV.

\section{Total Revenue}

Total Revenue NPV $=$ First Sales + Second Sales + Recycling Cost Saving.

First Sales $=$

$\sum_{d \in \mathrm{D}} \sum_{c \in C} \sum_{p \in P} \sum_{t \in T}\left(\left(Q_{d c p t} B_{d p} P_{p c t}\right) /(1+I R)^{t}\right)$

Second Sales $=$

$\sum_{r \in R} \sum_{\mathrm{k} \in \mathrm{C}} \sum_{p \in P} \sum_{t \in T}\left(\left(Q_{r l p t} B_{r p} P_{p l t}\right) /(1+I R)^{t}\right)$
Recycling cost saving $=$

$\sum_{a \in A} \sum_{s \in S} \sum_{p \in P} \sum_{t \in T}\left(\left(Q_{a s t} B_{a} W_{p}\left(\operatorname{Mat}_{s t}-R E C_{s t}\right)\right) /(1+I R)^{t}\right)$

\section{Total Cost}

The total cost equals the summation of the following twelve costs:

Fixed Costs:

$\sum_{t \in T}\left(\left(\begin{array}{l}\sum_{s \in S} F_{s} L_{s}+\sum_{f \in F} F_{f} L_{f}+\sum_{d \in D} F_{d} L_{d}+ \\ \sum_{a \in A} F_{a} L_{a}+\sum_{r \in R} F_{r} L_{r}+\sum_{l \in L} F_{l} L_{l}\end{array}\right) /(1+I R)^{t}\right)$

Material Cost:

$\sum_{t \in T}\left(\left(\sum_{s \in S} \sum_{f \in F} Q_{s t} B_{s} \operatorname{Mat}_{s t}\right) /(1+I R)^{t}\right)$

Manufacturing Costs:

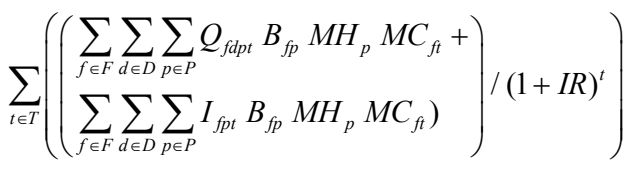

Non-Utilized Manufacturing Capacity Cost: 
$\sum_{\mathrm{f} \in \mathrm{F}}\left(\sum_{\mathrm{t} \in \mathrm{T}}\left(\left(\begin{array}{l}\left(\mathrm{CAPH}_{\mathrm{ft}}\right) \mathrm{L}_{\mathrm{f}}-\sum_{\mathrm{d} \in \mathrm{D}} \sum_{p \in P}\left(\mathrm{Q}_{\mathrm{fdpt}} \mathrm{B}_{\mathrm{fp}} \mathrm{MH}_{\mathrm{p}}\right) \\ -\sum_{\mathrm{d} \in \mathrm{D}} \sum_{p \in P}\left(\mathrm{I}_{\mathrm{ffpt}} \mathrm{B}_{\mathrm{ffp}} \mathrm{MH}_{\mathrm{p}}\right)\end{array}\right) N U C C_{f} /(1+I R)^{t}\right)\right)$

Shortage Cost (for distributor):

$\sum_{p \in P}\left(\sum_{c \in C}\left(\sum_{\mathrm{t} \in \mathrm{T}}\left(\sum_{1}^{\mathrm{t}} \mathrm{DEMAND}_{\mathrm{cpt}}-\sum_{1}^{t} \sum_{d \in D} \mathrm{Q}_{\mathrm{dcpt}} \mathrm{B}_{\mathrm{dp}}\right) /(1+I R)^{t}\right)\right)$

Purchasing Costs:

$\left.\sum_{t \in T}\left(\left(\sum_{c \in C} \sum_{a \in A} \sum_{\mathrm{p} \in \mathrm{P}} \mathrm{Q}_{\text {capt }} \mathrm{P}_{\mathrm{pct}} \mathrm{B}_{\mathrm{c}} \mathrm{QL}_{\mathrm{c}}\right)\right) /(1+I R)^{t}\right)$

Disassembly Costs:

$\sum_{t \in T}\left(\left(\sum_{c \in C} \sum_{a \in A} \sum_{\mathrm{p} \in \mathrm{P}} Q_{c a p t} B_{c} D A C_{a t}\right) /(1+I R)^{t}\right)$

Non-Utilized Remanufac. Capacity Cost:

$\sum_{\mathrm{f} \in \mathrm{F}}\left(\sum_{\mathrm{t} \in \mathrm{T}}\left(\begin{array}{l}\left(C A P R M_{f t}\right) L_{f}- \\ \sum_{\mathrm{r} \in \mathrm{R}} \sum_{p \in P}\left(Q_{f i p t} B_{f p} R M H_{p}\right)\end{array}\right) N U R C C_{f} /(1+I R)^{t}\right)$

Remanufacturing Costs:

$\sum_{t \in T}\left(\left(\sum_{f \in F} \sum_{r \in R} \sum_{p \in P} Q_{f r p t} B_{f p} R M H_{p} R M C_{f t}\right) /(1+I R)^{t}\right)$

Repairing Costs:

$\sum_{t \in T}\left(\left(\sum_{a \in A} \sum_{r \in R} \sum_{p \in P} Q_{a r p t} B_{a} W_{p} R E P C_{a t}\right) /(1+I R)^{t}\right)$

Disposal Costs:

$\sum_{t \in T}\left(\left(\sum_{a \in A} \sum_{l \in L} \sum_{p \in P} \mathrm{Q}_{\mathrm{alpt}} \mathrm{B}_{\mathrm{a}} \mathrm{W}_{\mathrm{p}} \operatorname{DISPC}_{\mathrm{lt}}\right) /(1+I R)^{t}\right)$

Transportation Costs:
(7) $\quad \sum_{\mathrm{t} \in \mathrm{T}}\left(\left(\sum_{s \in S} \sum_{f \in F} \mathrm{Q}_{\mathrm{sft}} \mathrm{B}_{\mathrm{s}} \mathrm{T}_{\mathrm{s}} \mathrm{DS}_{\mathrm{sf}}+\right.\right.$

$\sum_{f \in F} \sum_{d \in D} \sum_{p \in P} \mathrm{Q}_{\text {fdpt }} \mathrm{B}_{\mathrm{f}} \mathrm{W}_{\mathrm{p}} \mathrm{Tc}_{\mathrm{DS}}+$

$\sum_{f \in F} \sum_{d \in D} \sum_{p \in P} \mathrm{I}_{\mathrm{fdpt}} \mathrm{B}_{\mathrm{fp}} \mathrm{W}_{\mathrm{p}} \mathrm{T}_{\mathrm{f}} \mathrm{D}_{\mathrm{fd}}(1+S N)+$

$\sum_{d \in D} \sum_{c \in C} \sum_{p \in P} \mathrm{Q}_{\mathrm{dcpt}} \mathrm{B}_{\mathrm{dp}} \mathrm{W}_{\mathrm{p}} \mathrm{T}_{\mathrm{d}} \mathrm{D}_{\mathrm{dc}}+$

$\sum_{d \in D} \sum_{a \in A} \sum_{s \in S} \mathrm{Q}_{\text {aspt }} \mathrm{B}_{\mathrm{a}} \mathrm{W}_{\mathrm{p}} \mathrm{Tc}_{\mathrm{DS}}+$

$\sum_{d \in D} \sum_{a \in A} \sum_{f \in F} \mathrm{Q}_{\text {afpt }} \mathrm{B}_{\mathrm{a}} \mathrm{W}_{\mathrm{p}} \mathrm{Tc}_{\mathrm{DS}}+$

$\sum_{d \in D} \sum_{f \in F} \sum_{r \in R} \mathrm{Q}_{\mathrm{frpt}} \mathrm{B}_{\mathrm{f}} \mathrm{W}_{\mathrm{p}} \mathrm{Tc}_{\mathrm{DS}}+$

$\sum_{d \in D} \sum_{a \in A} \sum_{r \in R} \mathrm{Q}_{\text {arpt }} \mathrm{B}_{\mathrm{a}} \mathrm{W}_{\mathrm{p}} \mathrm{Tc}_{\mathrm{DS}}+$

$\sum_{d \in D} \sum_{a \in A} \sum_{l \in L} \mathrm{Q}_{\mathrm{alpt}} \mathrm{B}_{\mathrm{a}} \mathrm{W}_{\mathrm{p}} \mathrm{Tc}_{\mathrm{DS}}+$

$\left.\left.\sum_{d \in D} \sum_{r \in R} \sum_{k \in K} \mathrm{Q}_{\mathrm{rkpt}} \mathrm{B}_{\mathrm{r}} \mathrm{W}_{\mathrm{p}} \mathrm{Tc}_{\mathrm{rk}}\right) /(1+I R)^{t}\right)$

Inventory Holding Costs:

$\sum_{t \in T}\left(\left(\begin{array}{l}\sum_{f \in F} \sum_{p \in P} R_{f p t} W_{p} H F_{f}+ \\ \sum_{d \in D} \sum_{p \in P} R_{d p t} W_{p} H D_{d}\end{array}\right) /(1+I R)^{t}\right)$

\section{Constraints}

This section is a representation of the constraints of the model:

\section{Balance Constraints}

Balance constraints are given in the following Equation 17-29.

Factory Balance

$\sum_{s \in S} Q_{s f t} B_{s}=$

$\sum_{d \in D} \sum_{p \in P} Q_{f d p t} B_{f p p} W_{p}+I_{f p t} B_{f p} W_{p}, \forall t \in T, \forall f \in F$

Factory Store Balance:

$I_{f p t} B_{f p}+R_{f p(t-1)} B_{f p}=$

$R_{f p t} B_{f p}+\sum_{d \in D} I_{f d p t} B_{f p}, \forall t \in T, \forall f \in F, \forall p \in P$ 
Distributor Store Balance:

$\sum_{f \in F}\left(Q_{f d p t}+I_{f t p t}\right) B_{f p}+R_{d p(t-1)} B_{d p}=$

$R_{d p t} B_{d p}+\sum_{c \in C} Q_{d p p t} B_{d p}, \forall t \in 2 \rightarrow T, \forall d \in D, \forall p \in P$

Customer-in Balance:

$\sum_{d \in D} Q_{d c p t} B_{d p} \leq$ DEMAND $_{c p t}+\sum_{1 \rightarrow t}$ DEMAND $_{c p(t-1)}$

$-\sum_{d \in D} Q_{d c p(t-1)} B_{d p}, \forall t \in T, \forall c \in C, \forall p \in P$

Customer-out Balance:

$\sum_{a \in A} \mathrm{Q}_{\text {capt }} \mathrm{B}_{\mathrm{c}} \leq$

$\left(\sum_{d \in D} \mathrm{Q}_{\mathrm{dcp}} \mathrm{B}_{\mathrm{d}}\right) \mathrm{RR}, \forall \mathrm{t} \in \mathrm{T}, \forall \mathrm{c} \in \mathrm{C}, \forall \mathrm{p} \in \mathrm{C}, \forall p \in P$

Disassembly Location Balance:

$\sum_{c \in C} Q_{c a p t} B_{c}=\sum_{s \in S}\left(Q_{a s p t} B_{a}\right)+\sum_{f \in F}\left(Q_{a f p t} B_{a}\right)+\sum_{\mathrm{r} \in \mathrm{R}}\left(Q_{a p p t} B_{a}\right)+$

$\sum_{1 \in L}\left(Q_{a l p t} B_{a}\right), \forall t \in T, \forall a \in A, \forall p \in P$

Recycling Location Balance:

$\sum_{c=C}\left(Q_{\text {capt }} B_{c} R C\right)$

$=\sum_{s \in S}\left(Q_{a s p t} B_{a}\right), \forall t \in T, \forall a \in A, \forall p \in P$

Remanufacturing Balance:

$\sum_{c \in C}\left(Q_{\text {capt }} B_{c} R M\right)=$

$\sum_{f \in F}\left(Q_{a f p t} B_{a}\right), \forall t \in T, \forall a \in A, \forall p \in P$

Return Balance:

$\sum_{c \in C}\left(Q_{\text {capt }} B_{c} R P\right)=$

$\sum_{r \in R}\left(Q_{a r p t} B_{a}\right), \forall t \in T, \forall a \in A, \forall p \in P$

Disposing Location Balance:

$\sum_{c \in C}\left(Q_{\text {capt }} B_{c} R D\right)=$

$\sum_{l \in L}\left(Q_{a l p t} B_{a}\right), \forall t \in T, \forall a \in A, \forall p \in P$

Remanufacturing Balance:

$$
\begin{aligned}
& \sum_{a \in A}\left(Q_{a f p t} B_{a}\right)= \\
& \sum_{r \in R}\left(Q_{f p p t} B_{f}\right), \forall t \in T, \forall f \in F, \forall p \in P
\end{aligned}
$$

Redistribution Balance:

$$
\begin{aligned}
& \sum_{a \in A}\left(Q_{a r p t} B_{a}\right)+\sum_{f \in F}\left(Q_{f p p t} B_{f}\right)= \\
& \sum_{k \in K}\left(Q_{r p p t} B_{r}\right), \forall t \in T, \forall r \in R, \forall p \in P
\end{aligned}
$$

Second Customer Balance:

$\sum_{r \in R}\left(Q_{r k p t} B_{r}\right) \leq$

$D_{k p t}, \forall t \in T, \forall k \in K, \forall p \in P$

\section{Capacity Constraints}

Capacity constraints are given in the following Equation 30-38.

Supplier Capacity:

$\sum_{f \in F} Q_{s t t} B_{s} \leq C A P S_{s t} L_{s}, \forall t \in T, \forall a \in S$

Factory Material Capacity:

$\sum_{s \in S} Q_{s f t} B_{s} \leq C A P M_{f t} L_{f}, \forall t \in T, \forall f \in F$

Manufacturing Hours Capacity:

$\left(\sum_{d \in D} Q_{f d p t} B_{f p}+\sum_{\mathrm{d} \in \mathrm{D}} I_{f p t} B_{f p}\right) M H_{p} \leq C A P H_{f t} L_{f}$

$\forall t \in T, \forall f \in F, \forall p \in P$

Facility Store Capacity:

$\sum_{p \in P} R_{f p t} B_{f p} W_{p} \leq C A P F S_{f t} L_{f}, \forall t \in T, \forall f \in F$

Distributor Store Capacity:

$\sum_{f \in F} \sum_{p \in P}\left(Q_{f d p t}+I_{f d p t}\right) B_{f p} W_{p}+\sum_{p \in P} R_{d p t-1} B_{d p} W_{p} \leq$
$C A P D_{d t} L_{d}, \forall t \in T, \forall d \in D$

Disassembly Capacity:

$\sum_{s \in S} \sum_{p \in P} Q_{a s p t} B_{a} W_{p}+\sum_{f \in F} \sum_{p \in P} Q_{a f p t} B_{a} W_{p}+$

$\sum_{r \in R} \sum_{p \in P} Q_{a r p t} B_{a} W_{p}+\sum_{l \in L} \sum_{p \in P} Q_{a l p t} B_{a} W_{p} \leq$

$\operatorname{CAPA}_{l t}, \forall t \in T, \forall a \in A$ 


\section{Redistributors Capacity:}

$\sum_{k \in K} \sum_{p \in P} Q_{r k p t} B_{r} W_{p} \leq C A P R_{r t}, \forall t \in T, \forall r \in R$

Recycling Capacity:

$\sum_{a \in A} \sum_{p \in P} Q_{a s p t} B_{a} W_{p} \leq C A P R C_{s t}, \forall t \in T, \forall s \in S$

\section{Disposal Capacity:}

$\sum_{a \in A} \sum_{p \in P} Q_{a l p t} B_{a} W_{p} \leq P C_{p t}, \forall t \in T, \forall l \in L$

\section{Results and Analysis}

The results of the proposed model with the objective of maximizing the NPV of the CLSCN for multi-periods and multi-products are introduced in this section. The results are discussed to show the behavior production, storing and distribution plans and the corresponding optimal networks at different values of interest rates and maximum return ratios. The effect of interest rates on cost parameters is also introduced.
Operating parameters of the network are assumed as given in Table 1. The returned products purchasing price may be assumed as a fixed, random, or depends on the quality of the returned products. The demand patterns are assumed similar for all customers and all products as shown in Table 2.

\section{Effect of Interest Rate Change on the Costs, Revenues and Profit NPV}

A planning horizon of 12 periods is considered as shown in Table 2. The cash flow diagram is obtained for each of the applied interest rate ranging from $0 \%$ and $10 \%$ per planning period.

Figures 2 and 3 illustrate the relation between the various costs and revenues with the interest rates. It can be noticed that the NPV of all costs and revenues decrease with the increase of interest rates. Consequently, it is expected that NPV decreases with the increase of interest rates used for discounting the cash flows. Since the reduction in the NPV depends on the cash flow amount and the interest rate, the low-value costs and revenues are slightly affected. Figure 4 shows the interest rate effect on the NPV of total revenue, total cost and total profit at a rate of return of $50 \%$.

Table 1. The model parameters.

\begin{tabular}{|c|c|c|c|}
\hline Parameter & Value & Parameter & Value \\
\hline Virgin products prices & 100,150 and 200 & Supplier locations fixed costs. & 10,000 \\
\hline Weights of the three products & 1,2 and $3 \mathrm{Kg}$. & Factory location fixed costs. & 50,000 \\
\hline Manufacturing time of each product & 1,2 and $3 \mathrm{~h}$. & Distributor locations fixed costs. & 5,000 \\
\hline Remanufacturing time of each product & 2,3 and $4 \mathrm{~h}$. & Disassembly location fixed costs. & 2,000 \\
\hline Second customer demand for each product in each period & 500 & Redistribution location fixed costs. & 2,000 \\
\hline Second products price ratio & $80 \%$ & Disposal location Fixed costs. & 1,000 \\
\hline Returned products quality (may be random) & $20 \%$ & Supplier recycling capacity (kg) & 2,000 \\
\hline Material cost per kilogram & 10 & Supplier capacity (kg) & 4,000 \\
\hline Manufacturing costs per unit & 10 & Factory store capacity & 2,000 \\
\hline Shortage cost for each product per period & 5,10 and 15 & $\begin{array}{l}\text { Factory raw material } \\
\text { storing capacity }(\mathrm{kg})\end{array}$ & 4,000 \\
\hline Non-Utilized manufacturing capacity cost & 10 & $\begin{array}{l}\text { Factory manufacturing capacity } \\
\text { (hours) }\end{array}$ & 6,000 \\
\hline Non-Utilized remanufacturing capacity cost & 10 & $\begin{array}{l}\text { Factory remanufacturing capacity } \\
\text { (hours) }\end{array}$ & 2,000 \\
\hline Factory holding cost & 3 & Distributor store capacity & 4,000 \\
\hline Distributor holding cost & 2 & Disassembly location capacity & 2,000 \\
\hline Disassembly cost per unit & 3 & Redistribution capacity & 2,000 \\
\hline Recycling cost per unit & 5 & Disposal location capacity & 1,000 \\
\hline Remanufacturing cost per unit & 10 & Maximum return ratio & $50 \%$ \\
\hline Repairing cost & 5 & Repairing ratio & $50 \%$ \\
\hline Disposal cost & 1 & Recycling ratio & $10 \%$ \\
\hline $\begin{array}{l}\text { Max number of operating suppliers, factories, } \\
\text { distributors, disassembles and redistributors }\end{array}$ & 3 & Remanufacturing ratio & $30 \%$ \\
\hline Max number of first customers & 4 & Disposal ratio & $10 \%$ \\
\hline Max number of second customers & 2 & Batch sizes & 1 \\
\hline
\end{tabular}

Table 2. The demand of each first customer in each period for each product

\begin{tabular}{lllllllllllll}
\hline Period & 1 & 2 & 3 & 4 & 5 & 6 & 7 & 8 & 9 & 10 & 11 & 12 \\
\hline Demand & 100 & 200 & 300 & 400 & 500 & 600 & 600 & 500 & 400 & 300 & 200 & 100 \\
\hline
\end{tabular}




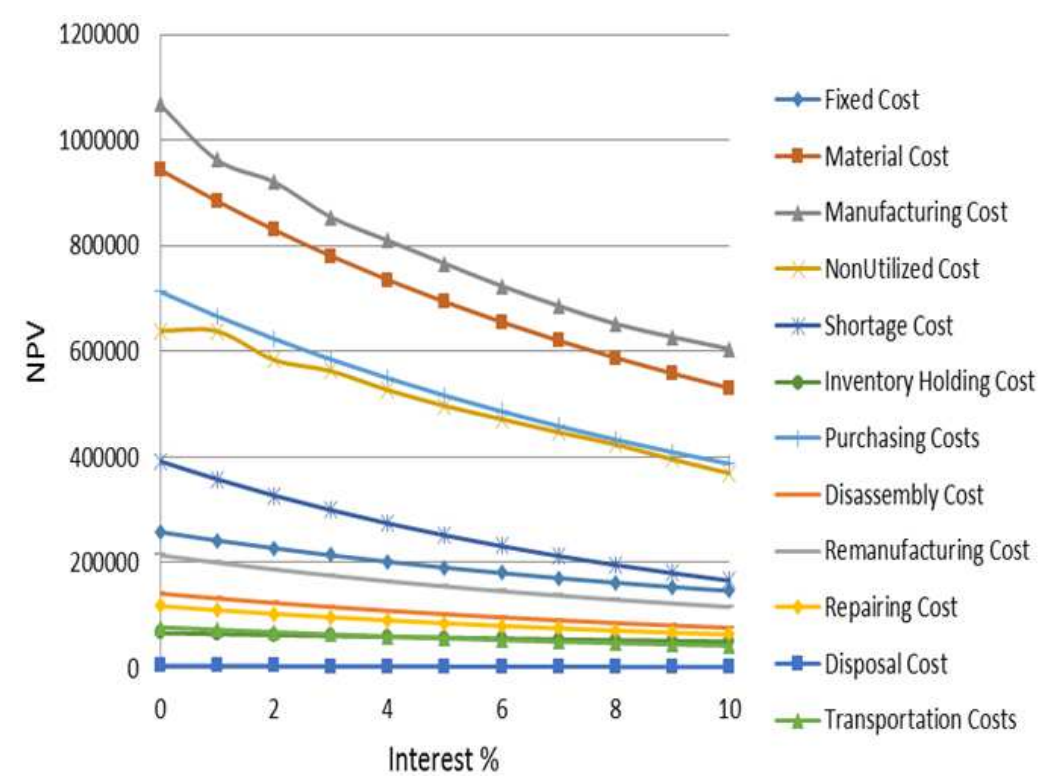

Fig. 2. Interest rate effect on the various costs NPV $(\mathrm{RR}=50 \%)$

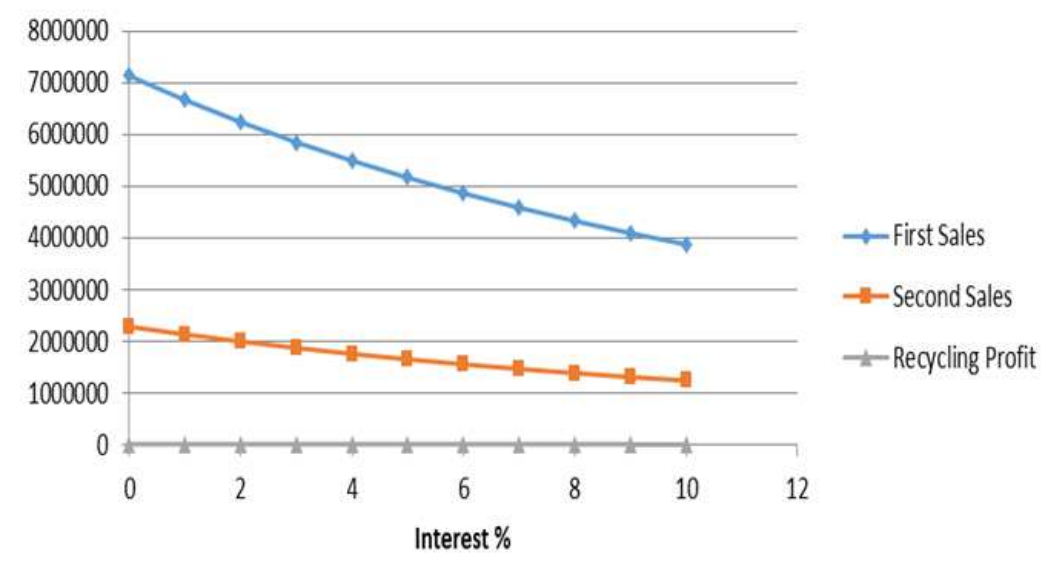

Fig. 3. Interest rate effect on the revenues NPV $(R R=50 \%)$

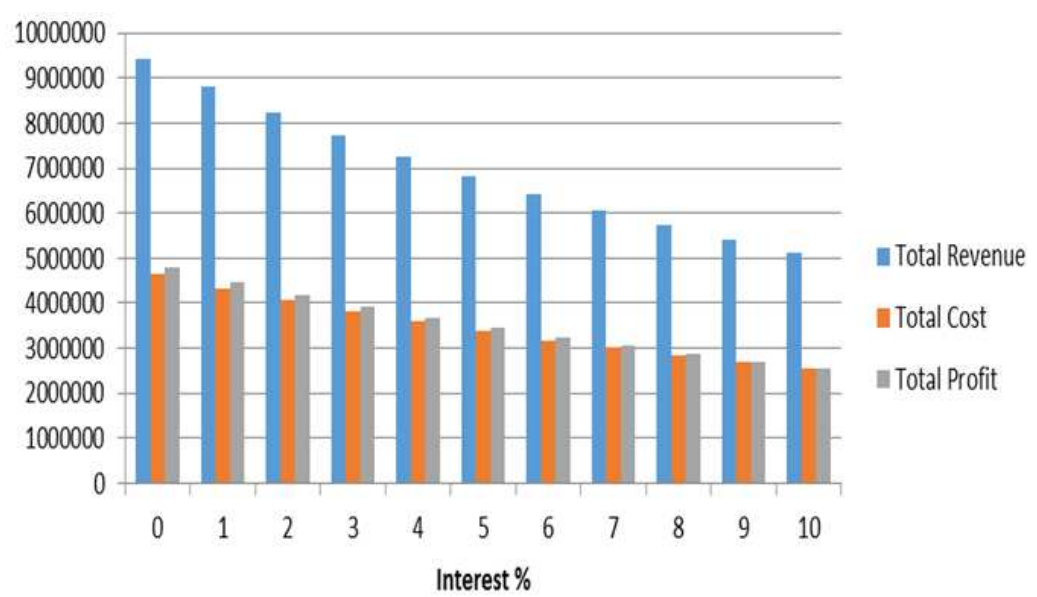

Fig. 4. Interest rate effect on the NPV of total revenue, cost and profit $(\mathrm{RR}=50 \%)$ 


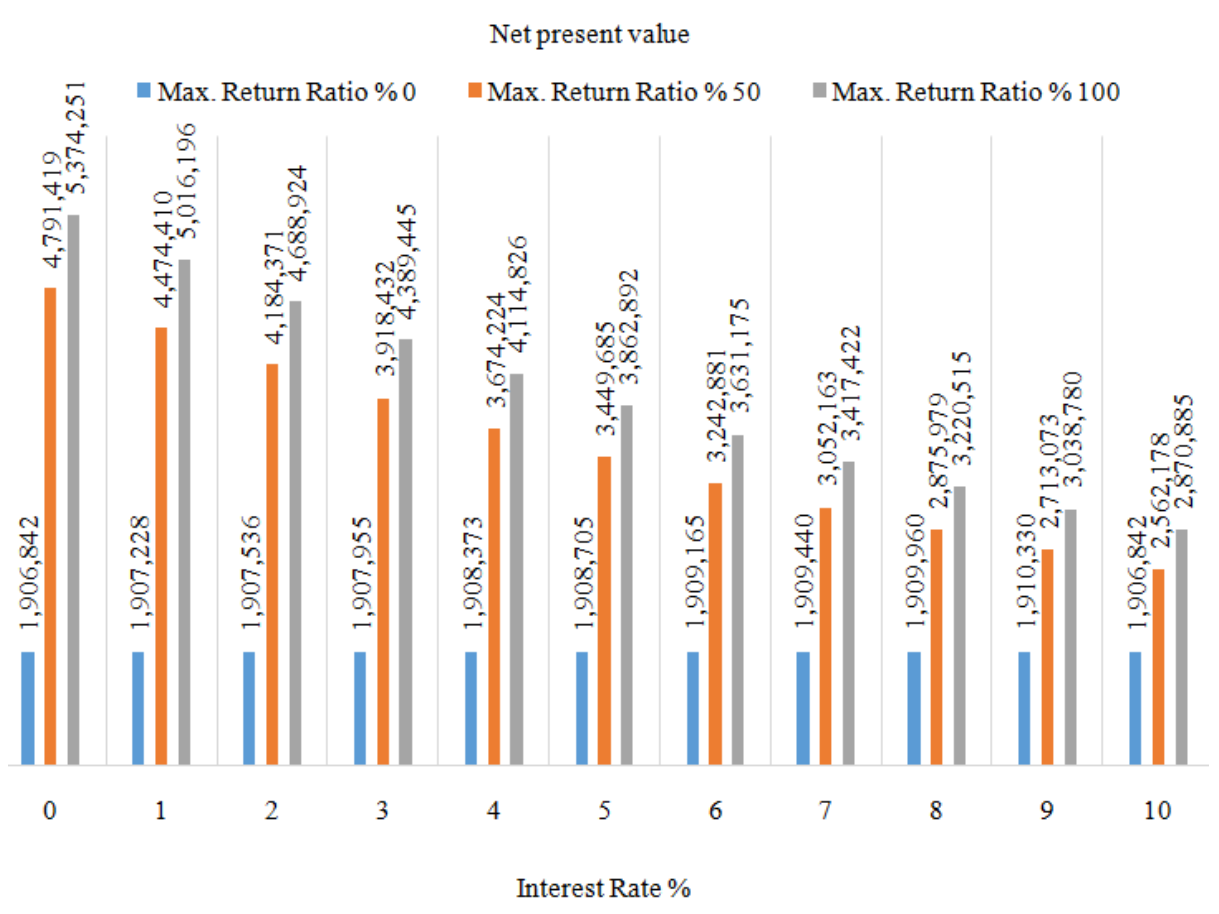

Fig. 5. The rate of return Vs. NPV

\section{Effect of the Maximum Rate of Return Change on $N P V$}

In this section, the effect of maximum return rate on the NPV of profit is examined and discussed at different interest rates ranging from 0 to $10 \%$. Three rates of returns 0,50 and $100 \%$ are considered to cover the study. Figure 5 illustrates the results of this study. The following can be concluded:

At $\mathrm{RR}=0 \%$ for all interest rates ranging from $0 \%$ to $10 \%$, the NPV of profit is almost the same. A slight difference with the change in the interest rate can be observed. This is logic; as the network, in this case, has no reverse chain as it acts only in the forward direction. This means that the variation of the interest rate does not have a great influence on the design of the supply chain structure under study.

It is clear that at each interest rate, the NPV of profits increases with the increase of maximum return ratio. This means that the increase occurred due to second sales and recycling profit covered the increase occurred in manufacturing, purchasing, disassembly, remanufacturing, repairing, disposal and transportation costs and exceeds over it.

It can also be noticed that as mentioned before, the NPV of the profit is decreased with the increase of the interest rates for the all different ratios of the maximum rate of return. This was expected due to the increase of discounting ratio known as the interest rate of return.

\section{Effect of Interest Rate Change on the Network Configuration}

Three cases mentioned in Table 3 are assumed to study the effect of the interest rate and maximum return ratio on the network configuration. Table 3 also summarizes the structures of the networks at the three different cases. Figure 6-8 show the change in the configuration of the networks at different corresponding cases. The following can be concluded from the obtained results:

The resulting network of case 1 where $R R=0$ is shown in Fig. 6. As there are no returned products, the network is considered as an open loop. So, it can be concluded that the change in the interest rate had no effect on the configuration of the network.

Comparing the results of case 1 where IR $=0 \%$ and $\mathrm{RR}=0 \%$ with the results of case 2 where $\mathrm{IR}=0 \%$ and $\mathrm{RR}=50 \%$, it can be noticed that the time value of money wasn't taken into consideration in both cases which explain why the first sales are the same for both cases as it is clear from Table 4 which is presented graphically in Fig. 9.

Different networks were resulted in both cases due to the change in the maximum rate of product returns causing the change of the network from open loop to closed loop supply chain as shown in Fig. 7 compared with Fig. 6. This change explains the reason of increasing the fixed cost in Case 2.

It is worth to mention that the configuration of the network of Case 3 where IR $=10 \%$ and $\mathrm{RR}=50 \%$ is the same for all values of interest rates from 1 to $10 \%$. The 
corresponding network is shown in Fig. 8. All networks have the same number of suppliers, facilities, distributors, assemblies, redistributors and disposal, but the links and quantities transferred among them are different. This means that the variation of the interest rate does not have a great influence on the design of the supply chain structure under study, but it has an effect on the transferred quantities due to taking the time value of money into consideration.

It is concluded in case 3 that with reverse logistics, there is a reduction in material and manufacturing costs as the returned products are re-used.

Table 3. Structures of the networks at different cases

\begin{tabular}{lllllllll}
\hline Case & IR $\%$ & RR $\%$ & S & F & D & A & R & L \\
\hline 1 & 0 & 0 & S1,S3 & F1,F3 & D1,D2,D3 & - & - & A1,A2,A3 \\
2 & 0 & 50 & S1,S3 & F1,F3 & D1,D2,D3 & R1,R2,R3 & L2 \\
3 & 10 & 50 & S1,S3 & F1,F3 & D1,D2,D3 & A1,A2,A3 & R1,R2,R3 & L2 \\
\hline
\end{tabular}

Table 4. Costs, revenues and profits of the three cases

\begin{tabular}{llll}
\hline Case & 1 & 2 & 3 \\
\hline Interest Rate (IR) \% & 0 & 0 & 10 \\
Maximum Return Ratio (RR) \% & 0 & 50 & 50 \\
First Sales & $7,133,200$ & $7,133,000$ & $3,873,226$ \\
Second Sales & 0 & $2,282,560$ & $1,239,432$ \\
Recycling Profit & 0 & 12,065 & 6,590 \\
Fixed Cost & $-180,000$ & $-258,000$ & $-146,494$ \\
Material Cost & -943980 & -944000 & -530550 \\
Manufacturing Cost & -1042240 & -1067160 & -604863 \\
Non-Utilized Cost & -877760 & -638850 & -369131 \\
Shortage Cost & -392040 & -392000 & -166017 \\
Inventory Holding Cost & -66814 & -66810 & -50536 \\
Purchasing Costs & 0 & -713300 & -387323 \\
Disassembly Cost & 0 & -141600 & -76656 \\
Remanufacturing Cost & 0 & -213990 & -116197 \\
Repairing Cost & 0 & -118000 & -63880 \\
Disposal Cost & 0 & -4720 & -2555 \\
Transportation Costs & -48650 & -77776 & -42868 \\
Total Revenue & 7133200 & 9427625 & 5119249 \\
Total Cost & 3551484 & 4636206 & 2557071 \\
NPV & 3581716 & 4791419 & 2562178 \\
\hline
\end{tabular}



Fig. 6. Structure of the CLSCN for case 1 . (IR $=0 \%, R R=0 \%)$ 


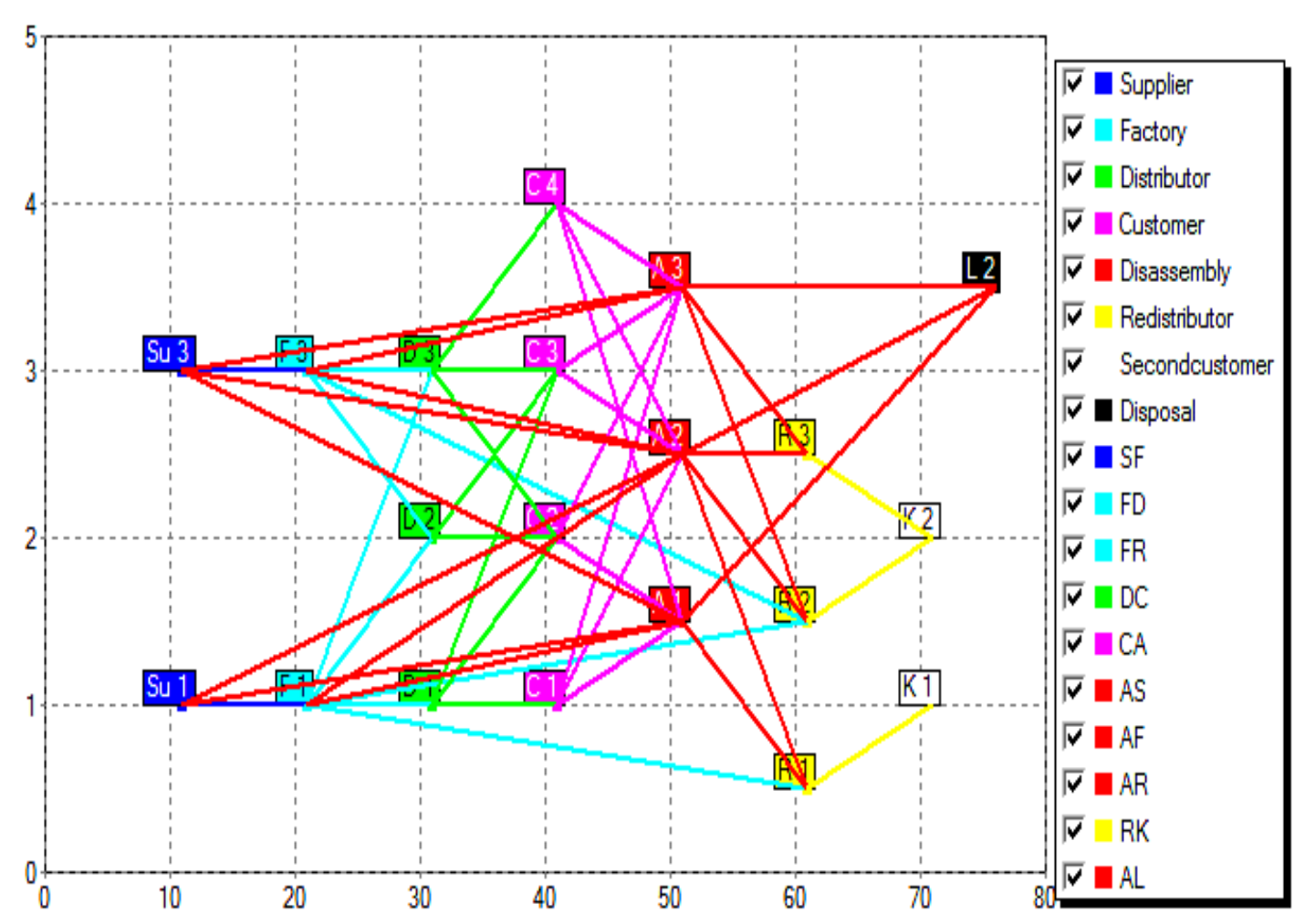

Fig. 7. Structure of the $\mathrm{CLSCN}$ for case 2 . (IR $=0 \%, \mathrm{RR}=50 \%)$

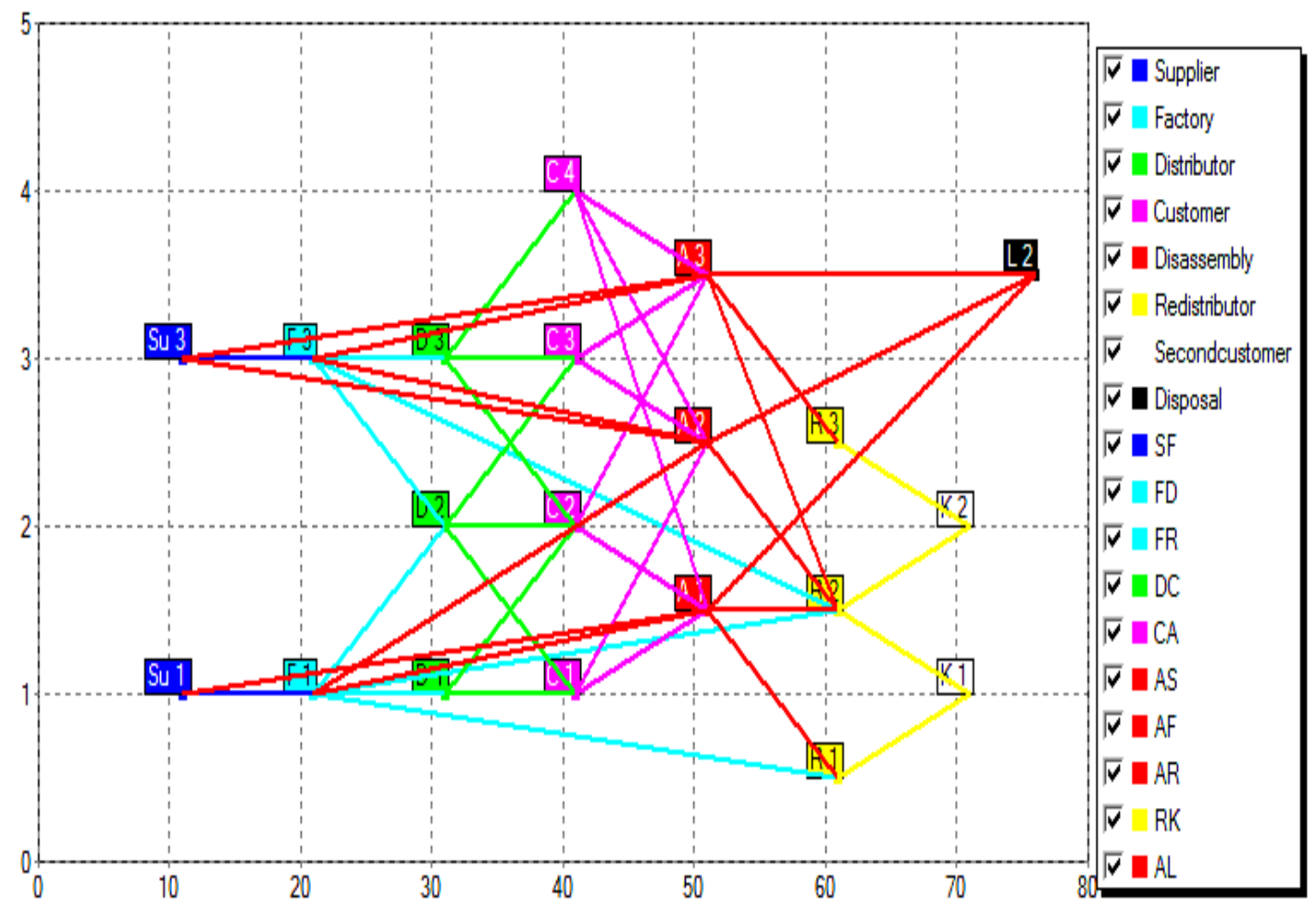

Fig. 8. Structure of the CLSCN for Case $3(\mathrm{IR}=10 \%, \mathrm{RR}=50 \%)$ 


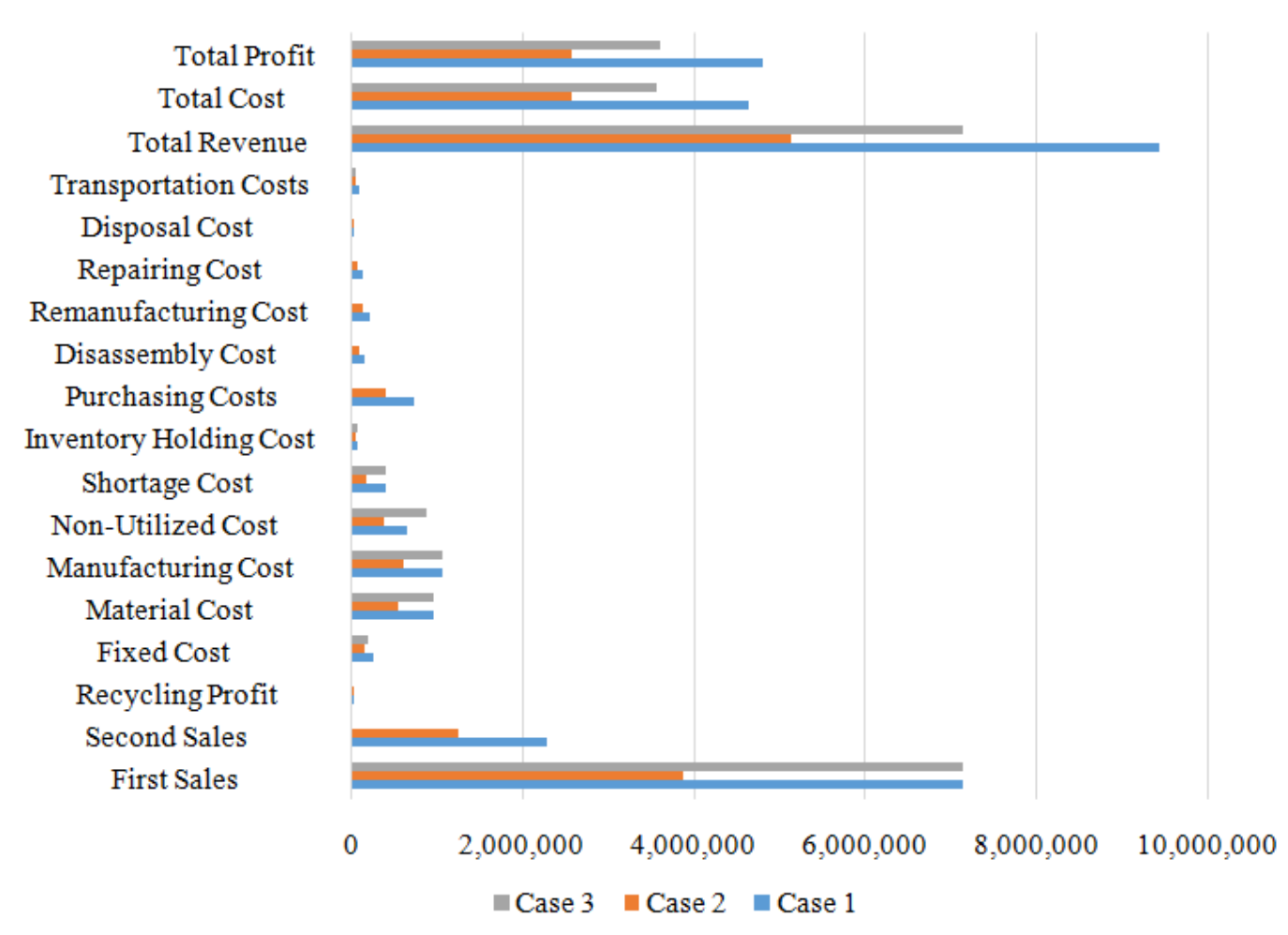

Fig. 9. Comparison of the results of the 3 cases

\section{Conclusion}

From the previous study, the following conclusions can be derived:

- The proposed model is successful in designing forward-reverse logistics networks while considering multi-product in multi-period with three echelons (suppliers, factories and distributors) in the forward direction and two echelons (disassembly and re-distributors) in the reverse direction

- The problem of CLSCN should be tackled from the economical point of view. Considering the time value of money affects the designing and planning of the network

- The quality level of the returned products, maximum return ratio and others may be tackled as a random value, but it is assumed as known to facilitate discussion

- This model can be customized easily to match a wide range of practical cases

It is recommended to:

- Take the time value of money into consideration

- Tackle the robustness of environmental parameters

- Take the percent defective of each facility into consideration

\section{Acknowledgement}

The authors would like to thank FICO Ltd. for their technical support.

\section{Funding Information}

There is no funder of this manuscript.

\section{Author's Contributions}

The first author developed the model and coded it using Mosel language. The second author reviews the literature while both authors participate in the design of experiments, analyzing the results and writing the manuscript.

\section{Ethics}

This article is original and contains unpublished material. The corresponding author confirms that all of the other authors have read and approved the manuscript and no ethical issues involved

\section{References}

Baptista, S., M.I. Gomes and A.P. Barbosa-Póvoa, 2013. A stochastic model for a multi-period multi-product closed loop supply chain. Proceedings of the 16th Congresso da Associacao Portuguesa de Investigaçao Operacional, (PIO’ 13), Bragança, Portugal, pp: 27-37. 
Diabet, A., D. Kannan, M. Kaliyan and D. Svetinovic, 2013. An optimization model for product returns using genetic algorithms and artificial immune system. Resources Conserv. Recycl., 74: 156-169. DOI: 10.1016/j.resconrec.2012.12.010

El-Sayed, M., N. Afia and A. El-Kharbotly, 2010. A stochastic model for forward-reverse logistics network design under risk. Comput. Indust. Eng., 58: 423-431. DOI: 10.1016/j.cie.2008.09.040

Franca, R.B., E.C. Jones, C.N. Richards and J.P. Carlson, 2010. Multi-objective stochastic supply chain modeling to evaluate tradeoffs between profit and quality. Int. J. Product. Econom., 127: 292-299. DOI: $10.1016 /$ j.ijpe.2009.09.005

Hatefi, S.M. and F. Jolai, 2014. Robust and reliable forward-reverse logistics network design under demand uncertainty and facility disruptions. Applied Math. Modell., 38: 2630-2647. DOI: $10.1016 /$ j.apm.2013.11.002

Jindal, A., K.S. Sangwan and S. Saxena, 2015. Network design and optimization for multi-product, multitime, multi-echelon closed-loop supply chain under uncertainty. Proc. CIRP, 29: 656-661.

DOI: 10.1016/j.procir.2015.01.024

Lee, D.H. and M. Dong, 2009. Dynamic network design for reverse logistics operations under uncertainty. Transport. Res. Part E, 45: 61-71.

DOI: $10.1016 /$ j.tre.2008.08.002
Ramezani, M., M. Bashiri and R. Tavakkoli-Moghaddam, 2013. A robust design for a closed-loop supply chain network under an uncertain environment. Int. J. Adv. Manufact. Technol., 66: 825-843. DOI: $10.1007 / \mathrm{s} 00170-012-4369-8$

Subulan, K. and A.S. Tasan, 2013. Taguchi method for analyzing the tactical planning model in a closedloop supply chain considering remanufacturing option. Int. J. Adv. Manufact. Technol., 66: 251-269. DOI: $10.1007 / \mathrm{s} 00170-012-4322-\mathrm{x}$

Vahdani, B. and M. Mohammadi, 2015. A bi-objective interval-stochastic robust optimization model for designing closed loop supply chain network with multi-priority queuing system. Int. J. Product. Econom., 170: 67-87. DOI: $10.1016 /$ j.ijpe.2015.08.020

Vahdani, B., 2015. An optimization model for multiobjective closed-loop supply chain network under uncertainty: A hybrid fuzzy-stochastic programming method. Iran. J. Fuzzy Syst., 12: 33-57.

Zeballos, L.J., C.A. Mendez and A. Barbosa Póvoa, 2016. Design and planning of closed-loop supply chains: A risk-averse multistage stochastic approach. Indust. Eng. Chem. Res., 55: 6236-6249. DOI: $10.1021 /$ acs.iecr.5b03647 